\title{
OPERATIONAL OCEANOGRAPHY AND PREDICTION - A GODAE PERSPECTIVE
}

\author{
P.Y. Le Traon', M. Rienecker ${ }^{2}$, N. Smith ${ }^{3}$, P. Bahurel ${ }^{4}$, M. Bell ${ }^{5}$, H. Hulburt ${ }^{6}$, P. Dandin', \\ M. Clancy ${ }^{8}$ and C. Le Provost ${ }^{9}$
}

\author{
${ }^{1} C L S$, Toulouse, France, ${ }^{2} G S F C$, Washington, USA, ${ }^{3} B M R C$, Melbourne, Australia, \\ ${ }^{4}$ SHOM/BRESM, Toulouse, France, ${ }^{5} U K M O$, Bracknell, UK, 'NRL, Stennis Space Center, USA, \\ ${ }^{7}$ FMTO, Toulouse, France, ${ }^{8}$ FNMOC, Monterey, USA, ' LEGOS, Toulouse, France
}

\section{1 - INTRODUCTION}

In early 1997, the Global Ocean Data Assimilation Experiment (GODAE) concept emerged from discussions of the Ocean Observation Panel for Climate (OOPC). The concept was developed in the belief that attracting the resources necessary for an adequate long-term global ocean observing system for monitoring the ocean depends upon a clear demonstration of feasibility and value of such a system (Smith and Lefebvre, 1997). Using the First GARP Global Experiment (FGGE) as a model, OOPC proposed GODAE as an experiment in which a comprehensive, integrated observing system would be established and held in place for several years and the data assimilated into stateof-the art models of the global ocean circulation in near real-time.

This paper gives an overview of GODAE focusing on aspects relevant to the development of a global ocean observing system and to the demonstration of its scientific and practical societal benefits. A general overview of GODAE is first given. The main operational applications which are expected to benefit from the global and integrated approach of GODAE are then presented. User requirements are identified and we try to appraise the benefits of the integrated and global GODAE approach for meeting these requirements. We then proceed to the relationship between GODAE and the design/development of an ocean observing system : what are the GODAE data requirements and how GODAE should help to assess, improve and sustain the observing system ? The main scientific and technical issues related to the successful development of GODAE are finally discussed.

\section{2 - OVERVIEW OF GODAE}

\section{1 - Why a Global Ocean Data Assimilation Experiment ?}

GODAE is fired by both opportunity and need. The opportunities arise because of the development and maturity of remote and direct observing systems, making global real-time observation feasible; the steady advances in scientific knowledge and our ability to model the global ocean and assimilate data at fine space and time scales; the genuine enthusiasm of the community to promote and implement integrated global observing systems; and the critical advances provided by research programs like TOGA and WOCE. An examination of the satellite schedules that are firm suggests that, from the aspect of the satellites alone, 2003-2005 would be a good time to mount a demonstration of feasibility and practicality, assuming satellite agencies can be convinced to stay with the present schedules. The modeling and data assimilation community still faces considerable challenges but, drawing a line from developments over the previous decade, and noting the concerted effort being mounted by WOCE, it is reasonable to assume that these components will be sufficiently advanced by this time. With the ARGO project (Roemmich et al., this issue) and other 
in situ components, we have the potential for global direct sampling of the ocean, at least at the important large scales, if effort and resources can be gathered and focussed for the target period.

The needs are of two types. First, there does appear to be a genuine user demand for global ocean products, for a range of time and space scales. The second need concerns the future of ocean science, ocean observing systems, and the associated infrastructure. A capability for providing regular ocean analyses is required as a framework for scientific research and development. Also, if we are to build a future with a robust, routine permanent and well-supported network of ocean observations, then a clear and convincing demonstration of the feasibility and practicality of maintaining such a network is required.

\section{2 - Objectives and scope of GODAE}

GODAE is a practical demonstration of real-time global ocean data assimilation in order to provide a regular, complete depiction of the ocean circulation at time scales of a few days, space scales of several tens of kilometers, and consistent with a suite of space and direct measurements and appropriate dynamical and physical constraints. GODAE is also needed to successfully implement a global ocean observing system and to establish a strong partnership between the operational observing system and research. GODAE is focussed towards:

$\Rightarrow$ the application of state-of-the art ocean models and assimilation methods for operational oceanography such as Naval and maritime safety applications, for boundary conditions to extend predictability of coastal and regional subsystems, and for initial conditions of climate forecast models.

$\Rightarrow$ the production of global ocean analyses for developing improved understanding of the oceans, improved assessments of the predictability of ocean systems, and as a basis for improving the design and effectiveness of the global ocean observing system.

The goals in terms of outcomes include:

- improved predictability of coastal, shelf and regional subsystems through the provision of suitable oceanic boundary conditions,

- provision of better initial conditions for climate predictions and analyses for validation of climate simulations,

- improved open ocean forecasts,

- integrated analyses or reanalyses for research programs (e.g. CLIVAR),

- description of the ocean circulation and physics upon which more specialized systems, such as ecosystem models, can be developed and tested,

- provide a foundation for hypothesis testing, process studies and further experimentation, much as is commonplace in numerical weather prediction today,

- provide a method for systematic handling, quality control and scientifically consistent interpretation (analysis) of additional data sets such as those from process studies and arising from incidental exploration,

- assessment of utility of new ocean data sets (e.g. new altimetric missions, sea surface salinity from satellites),

- model testing and improvement through data assimilation,

- a viable, long-term observing system for GOOS. 
The design of the observing system, the modeling and data assimilation, and the types of products generated by GODAE are inextricably linked to the overall scope and objectives adopted for GODAE. Subsequent to the OOPC discussions, international working groups have refined the scope of GODAE to focus on the complementary but mutually synergistic areas of real-time $(<1-2$ days $)$, high resolution (eddy resolving) operational oceanography, and near real-time $(<1-2$ weeks) and delayed mode climate applications.

\section{3 - General strategy for GODAE}

Several overarching principles are behind the development of a strategy for GODAE:

- GODAE is not a scientific experiment. It is a practical exercise or demonstration of the utility and feasibility of real-time global ocean data assimilation.

- GODAE requires the leading-edge developments of ocean modeling, data assimilation and observational networks. It requires scientific and technical developments of high complexity and sophistication.

- GODAE is working toward delivery time frames (near-real-time) and a mode (operational) that are not familiar to many oceanographers.

GODAE is thus a novel and challenging concept. It will require innovation, astute scientific appraisal and visionary but practical planning. The components necessary for this experiment can only be achieved through international cooperation and coordination. GODAE needs to optimize the flow of measured information and the advance of relevant research (i.e. capitalizing on WOCE and TOGA) and technology (in situ and space observing systems, computer architecture, communication systems).

The realization of GODAE depends on the real-time availability and coordination of several elements: remotely-sensed and in situ observations; data processing, management and delivery; global state estimation and modeling; and delivery of products to user communities. It also depends on adherence to the principles governing GODAE: free, open and timely exchange of data and products; diversity in applications; real-time, global products. The challenging scope of GODAE calls especially for closely coordinated efforts between data providers and scientists undertaking ocean data assimilation.

\section{4 - GODAE organization}

GODAE will evolve through phased development from the present to 2005, progressing from integration of current activities on national and international levels, further development of the infrastructure including data set development and data and product delivery, to the operational phase and realization of the experiment's societal benefits.

The structure of GODAE is built on the facilitation by Patrons (program management) and the implementation by Partners. Central to this structure is the concept of a GODAE "Common" which consists of data, products, processing systems, models, which is common to and shared by all GODAE Partners. The expectation is that activities undertaken within GODAE will contribute to the development and growth of the Common. The coordination within this structure is facilitated through a GODAE office and an International GODAE Steering Team comprised of scientists from Australia, France, Japan, the United Kingdom, and the United States of America (Fig. 1). 


\section{GODAE ORGANISATION}

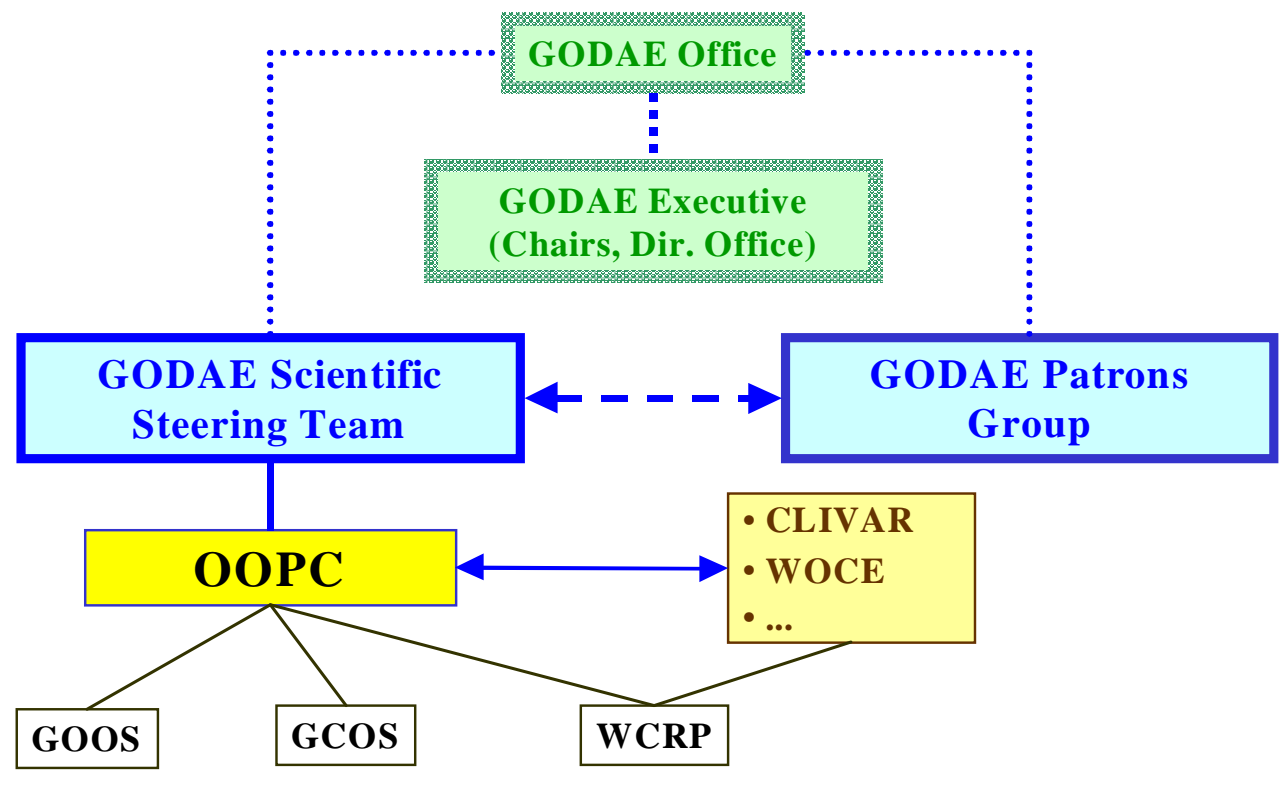

Fig.1 : GODAE organization

The strategy to realize the global objectives of GODAE is to develop the infrastructure through pilot projects, i.e. individuals and groups brought together to develop part of the GODAE Common. The pilot projects will:

- contribute to observing system design by, for example, investigating strategies for ARGO deployment,

- intercompare input data sets and define data error statistics,

- establish consistent quality control and data processing procedures,

- develop ancillary data sets as needed such as a high resolution SST product,

- establish reliable data delivery through distributed GODAE data servers,

- continue development of ocean state estimation methodologies,

- define methods and measures for model and data assimilation validation,

- work with constituencies to develop useful products and metrics to assess the outcomes of GODAE.

\section{5 - GODAE products and GODAE users}

The main GODAE products will be operational global mesoscale nowcast and forecast upper ocean fields and global, consistent 4D analyses of temperature, salinity and flow fields at the climate time and space scales. The outcome of GODAE is also expected to include a broader constituency for oceanographic models, assimilation products and observations and infrastructure to facilitate access to observations and assimilation products and to enhance interactions between observational and assimilation communities.

The constituencies targeted by GODAE are the intermediaries (mid-level users) who will enhance and emboss GODAE products for specific end users. GODAE products will form only the raw material from which a wide range of services for operational applications can be developed. The interaction of GODAE centers with end-users will thus be best developed through governmental/private application centers or specialized service providers that already have a direct connection with end-users and that have a keen interest in improving their services using the GODAE outputs. 


\section{3 - GODAE AND THE APPLICATIONS OF OPERATIONAL OCEANOGRAPHY}

A significant proportion of world economic and social activities depends on the sea. These activities are subject to uncertainty, loss of efficiency and direct costs and damages caused by the varying impact and hostility of the marine environment. To mitigate against such adverse effects and to ensure a sustainable, cooperative relationship with the marine environment, an accurate description and a reliable prediction of the ocean variations as well as an improved scientific understanding of factors controlling these changes are crucial. The GODAE belief is that this will be best achieved through a global and integrated approach combining model, in-situ and remote sensing data through data assimilation. Some of the main operational applications (climate and seasonal forecasting, navy applications, marine safety, fisheries, the offshore industry and management of shelf/coastal areas) that rely on information on the ocean physical state are discussed below. Who are the users and what are their needs ? What information do they use now and what GODAE can provide them in future ? How do we today assess the benefits of an "integrated" and global GODAE approach ?

\section{1 - Climate and Seasonal Forecasting}

Seasonal-to-interannual climate variations such as El Nino and La Nina impact weather patterns on a global scale and have the potential for strong economic impact in many countries because of the associated extreme variations in precipitation. The signatures of these variations, such as tropical Pacific sea surface temperature (SST), have timescales of 6-to-9 months, and have been shown to be at least partly predictable. In recent years advances have been made in two crucial areas to increase the ability of predicting El Nino events and their global teleconnections anywhere from a few months to more than a year in advance. First are the improvements in the numerical models of the atmosphere and ocean, and on the methods for coupling these components for short term climate prediction. Second are the substantial improvements in the observing system in the equatorial Pacific, both in the comprehensive in situ measurements of surface winds, sea surface temperature, upper ocean temperature, and upper ocean velocity from the Tropical Atmosphere Ocean (TAO) array (e.g. McPhaden et al., 1998), and in the complementary near global observations of sea surface temperature, sea level anomalies and surface winds from satellites.

In the development of prediction systems and in the attempts to understand the predictability of the coupled system, modelers and observationalists have focused on coupled processes in a narrow equatorial strip $\left(10^{\circ} \mathrm{S}-10^{\circ} \mathrm{N}\right)$ along which most of the oceanic action of El Nino occurs. Theory has concentrated interest in a few key observables: tropical precipitation patterns; surface wind stresses; equatorial Pacific SST; and, above all, subsurface fluctuations in the oceanic thermocline from which the system derives the memory that makes long-term predictions possible. The dominant scales of subsurface ocean variability in this region are about 10 degrees zonally, a few degrees meridionally and a month and longer (e.g. Meyers et al., 1991). Shorter scales are not well resolved by the observing system, and so ocean initialization in support of ENSO (El Nino - Southern Oscillation) forecasting focuses on accurate representation of this low frequency, low wavenumber variability. High quality surface forcing, particularly surface wind stress, is crucial to the initialization process (e.g. Chen et al., 1995; Stockdale et al., 1997), but there are numerous demonstrations (e.g., Ji et al. 1998) that ocean data assimilation improves the initial estimate of the ocean state by compensating for forcing errors and reducing biases due to deficiencies in model physical parameterizations and resolution. Current model resolution is typically about 1 degree, with finer meridional resolution in the equatorial oceans. Future implementations are likely to improve on this resolution only slightly as more emphasis is placed on ensemble prediction.

Routine analyses in support of seasonal-to-interannual prediction are now produced weekly or monthly using near real-time temperature observations available over the GTS. The background error covariance estimates used to produce these operational analyses (e.g. Behringer et al., 1998, 
Smith et al., 1991) are chosen to maximize the information in the larger scales in the initial ocean state estimate and minimize the small scale 'noise' which can degrade the predictions of ENSO. Analysis of the modes of error growth in these coupled forecasts indicate that to forecast SST anomalies in the eastern Pacific with an accuracy of $1^{\circ} \mathrm{C}$, sea level anomalies have to be initialized with an accuracy of $2-4 \mathrm{~cm}$ and SST with an accuracy of $0.2^{\circ} \mathrm{C}$ (David Behringer, pers. communication). With careful tuning of the background error statistics, useful forecasts up to one year in advance can often be achieved (e.g. Ji et al., 1998). However, predictive skill will still need to be improved considerably if ENSO prediction is to become a routine tool of policy making to mitigate the socio-economic impacts of ENSO-related climate variability. The key to this lies in improvements in both coupled models and ocean data assimilation systems.

The TAO observations will remain essential to ENSO forecasting for the foreseeable future; but, as we seek to explain and predict ENSO in much greater detail and investigate other elements of climate variability, an increase in the quality and coverage of oceanographic data will be a crucial ingredient to tapping the full predictability of the system. Altimeter measurements will be a key source of high quality, near-global data for assimilation. As current analysis systems start to assimilate sea surface height variations from TOPEX/POSEIDON (hereafter T/P) and ERS-1,-2, there is increasing evidence that the impact of salinity variations on surface height cannot be ignored (e.g. Maes, 1998; Ji et al., 1999). The importance of salinity variations is even greater in the other tropical oceans (e.g. Cooper, 1988) and will also be important at higher latitudes. The global salinity sampling of ARGO will be crucial to estimation of the multivariate background error statistics necessary for effective utilization of surface altimeter observations. This is especially true as the short-term climate prediction efforts expand beyond the tropical Pacific.

The need to extend ocean data assimilation for seasonal-to-interannual applications beyond the confines of the tropical Pacific is becoming evident as studies reveal relationships between SST patterns and precipitation. In the Atlantic, coherent fluctuations in temperature, rainfall, surface pressure and SST have impacts eastward on Europe, southward on West Africa, and westward on North and South America. For example, there is a weak mode of the tropical Atlantic oceanatmosphere variability similar to the Pacific ENSO which affects the rainfall in the Gulf of Guinea. Tropical North Atlantic SST anomalies are also related to rainfall variability over the Caribbean and Central America and over the southeastern U.S. where the relationship is opposite to that between Nino3 SST and rainfall anomalies (Enfield, 1996). Another example is the regional impact of South Atlantic SST anomalies on seasonal predictability of rainfall over Northeast Brazil (e.g. Hastenrath and Greishar, 1993).

GODAE, with an operational time span of at least 3 years, with international cooperation in the collection, sharing and distribution of global ocean observations and surface fluxes in near realtime, and with partnerships forged to improve ocean data assimilation methodology, will provide a unique opportunity to advance the capability of seasonal-to-interannual forecasting and analysis of climate variability at the global scale. Although improving coupled models themselves is one of the highest priorities for increasing prediction skill from seasonal to longer timescales (e.g. Ji et al., 1998), improvements in ocean data assimilation systems are also important (e.g. Behringer et al., 1998). The main GODAE product for climate and seasonal forecasting applications will thus be a better initial state of the global ocean (surface and deeper layers) for initialization of coupled ocean/atmosphere models. The benefits expected from GODAE also lie in the provision of improved assimilation methodologies (including better statistical characterization of observational and model errors), possibly improved models (ocean estimation is a powerful means to analyze model deficiencies), and assessments of the impact of global data coverage and data type for the prediction and analysis of major climate signals. In addition, a major benefit for the climate community will be afforded by the organization and ready availability of quality-controlled observations and surface forcing. 


\section{2 - Strategic and tactical applications}

Many nations have significant investment in strategic and tactical areas related to national defence and civilian protection. These areas are demanding users for operational oceanography. To support the full range of Naval requirements, the different operational models must have sufficient vertical resolution for adequate representation of transient, seasonal and permanent thermoclines, and surface and bottom mixed layers. For some applications, horizontal resolutions down to the order of $10 \mathrm{~km}$ in deep water and order $1 \mathrm{~km}$ in shallow water are needed. Naval applications for global eddy-resolving ocean analyses and predictions are numerous. They include optimum tracks for tactical exercises; search and rescue; anti-submarine warfare and surveillance; tactical planning; high resolution boundary conditions for even higher resolution coastal models; inputs to ice, atmospheric and bio-physical models and shipboard environmental products; environmental simulation and synthetic environments; observing system simulations; ocean research; pollution and tracer tracking and inputs to water quality assessment. With resolution finer than $10 \mathrm{~km}$ this includes accurate relocatable models for shipboard and other applications by extraction from the global model grid.

Part of these naval applications are shared with civil marine applications (e.g. marine safety, ship routing). However, the main interest of Navies is the improvement of nowcasts and forecasts of mesoscale ocean phenomena. That is, the horizontal and vertical depiction of ocean structures (eddies, fronts, current meanders) with typical space and time scales of 50 to $500 \mathrm{~km}$ and 10 to 100 days. Acoustics plays a major role in naval applications and the impact of mesoscale ocean perturbations on acoustic propagation is alone strong enough to justify the setting up of an operational oceanography monitoring of mesoscale features.

For many years, Navies have been promoting and developing new methods and tools to provide routine, reliable and near-real-time depiction and prediction of ocean state. Several agencies already operate ocean monitoring and prediction systems, some directly supported by the Navy, other indirectly (e.g., the UKMO). A few experiments demonstrating the power of integrated systems (involving the whole chain : observations, modeling and data assimilation, end-users applications) have been conducted. The continuous routine operation of ocean nowcast/forecast system (Giraud et al., 1997) (Fig.2) or Clancy and Moersdorf (1997) has demonstrated the importance of the " nearreal-time " requirement in ocean observation dissemination. The scales of ocean phenomena navies have an interest in generally require a near-real-time availability of observations for assimilation into the model; experience has clearly shown that near-real-time data delivery no longer implies a significant compromise in the accuracy for the end-user products. For example, from 1992 to 1999, the data delay for T/P and ERS altimeter data decreased from 8-15 days up to 2-3 days, leading to an improvement of the ocean prediction system performances. There is now a strong demand for rapid delivery of situ data (with a data delay reduced to a few hours).

For modeling and assimilation, the central issue is the horizontal resolution needed for the "eddyresolving" model and data assimilation since the dimension of the whole system (data network, assimilation and modeling methods, computing and archiving centers, etc) depends upon it. These resolution requirements are driven directly by naval applications and indirectly by resolution needs to accurately represent the physics and dynamics of oceanic phenomena which are relevant to naval applications. The need for resolution goes beyond the need to represent oceanic phenomena and becomes particularly important when (a) an ocean model must act as a skillful dynamical interpolator of data which is moderately sparse in relation to the phenomena of interest and almost entirely at the surface, and when (b) the model is used to perform forecasts. 


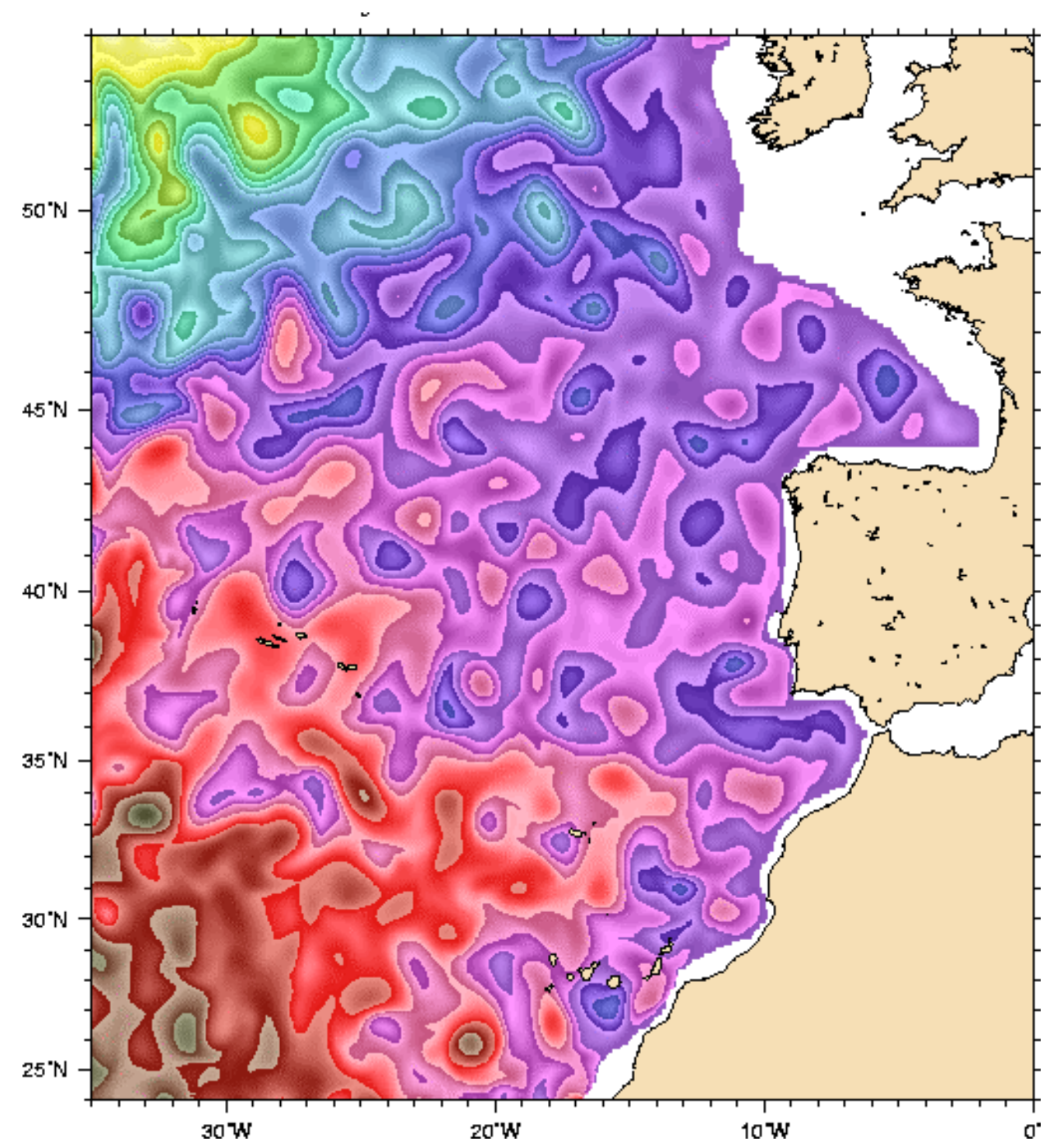

Fig. 2 : Example of a 7-day forecast of the upper surface transport obtained from the French Navy SOPRANE system in the Eastern North Atlantic.

This is especially challenging for mesoscale variability, such as oceanic eddies and meandering of ocean currents and fronts. This variability tends to be nondeterministic due to flow instabilities and is only qualitatively resolved by satellite altimetry. Given these challenges and the computational challenges, is global eddy-resolving ocean data assimilation and prediction even feasible during the GODAE time frame ? Recent modeling experiments give a strong indication that it is feasible. In particular, simulations performed from the NRL Layered Ocean Model with T/P and ERS-2 altimeter data assimilation indicate (1) that satellite altimetry is a suitable observing system for mesoscale oceanic features, (2) that an ocean model with high enough resolution can be a skillful dynamical interpolator for satellite altimeter data in depicting mesoscale oceanic variability, and (3) that the high resolution ocean model can provide skillful forecasts (better than persistence and climatology) of mesoscale variability for at least a month, when model assimilation of the altimeter data is used to define the initial state (see Fig.3 and Fig.4). Additional information on these results can be found in Hurlburt et al. (1999) and Smedstad et al. (1999). These experiments have also shown that a $14^{\circ}$ model is substantially less skillful as a dynamical interpolator and that it has substantially less forecast skill than a $1 / 16^{\circ}$ model. 

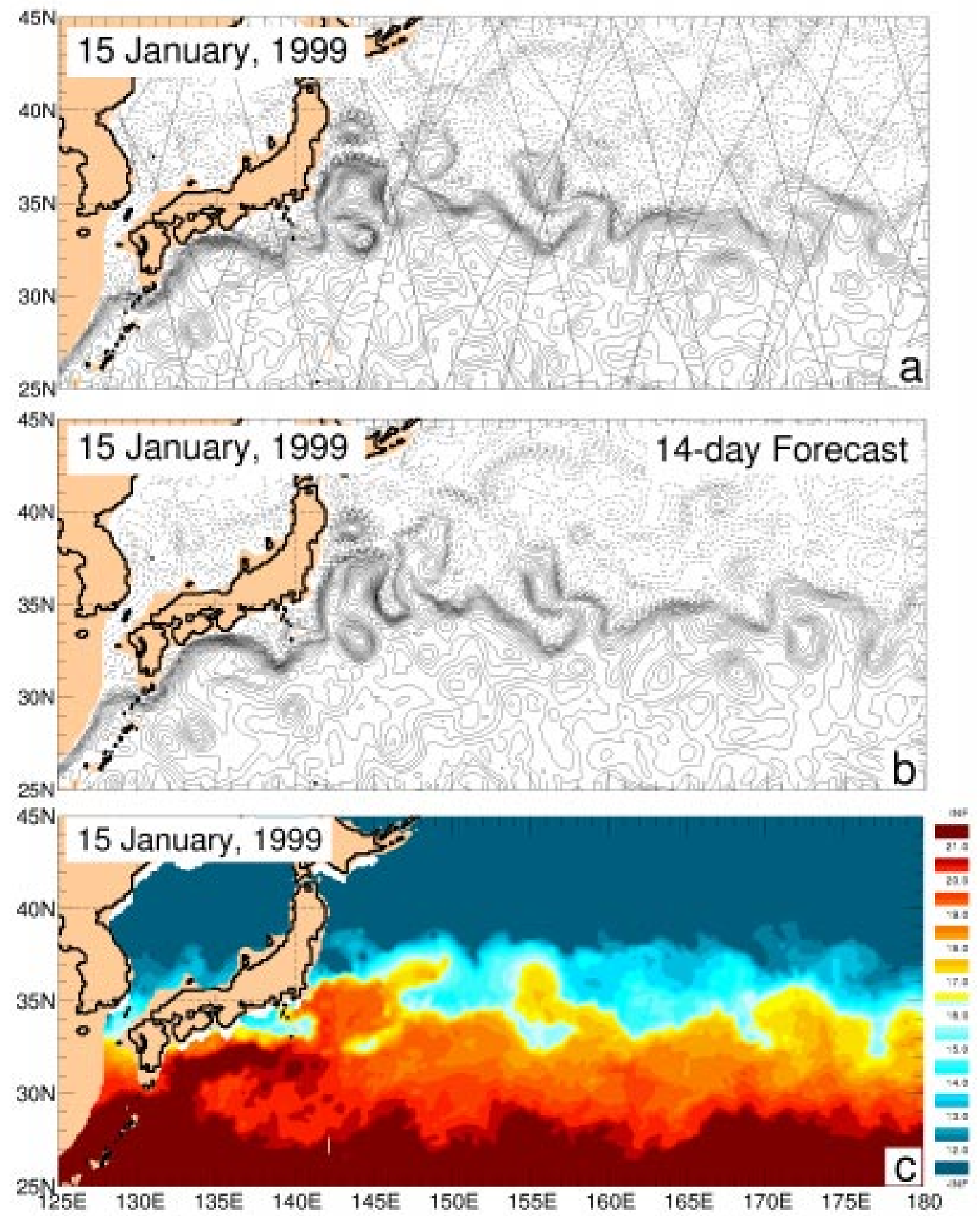

Fig. 3 : (a) Kuroshio region sea surface height snapshot (SSH) for January 15, 1999 from the NRL $1 / 16^{\circ}$ Pacific model with assimilation of T/P and ERS-2 data. (b) Corresponding SSH snapshot from a 14-day forecast initialized on January 1, 1999. (c) $1 / 8^{\circ}$ sea surface temperature (SST) analysis from satellite IR imagery. The contour intervals are $5 \mathrm{~cm}$ for SSH and $5^{\circ} \mathrm{C}$ for SST. 
Mean Kuroshio Pathway error vs Forecast length

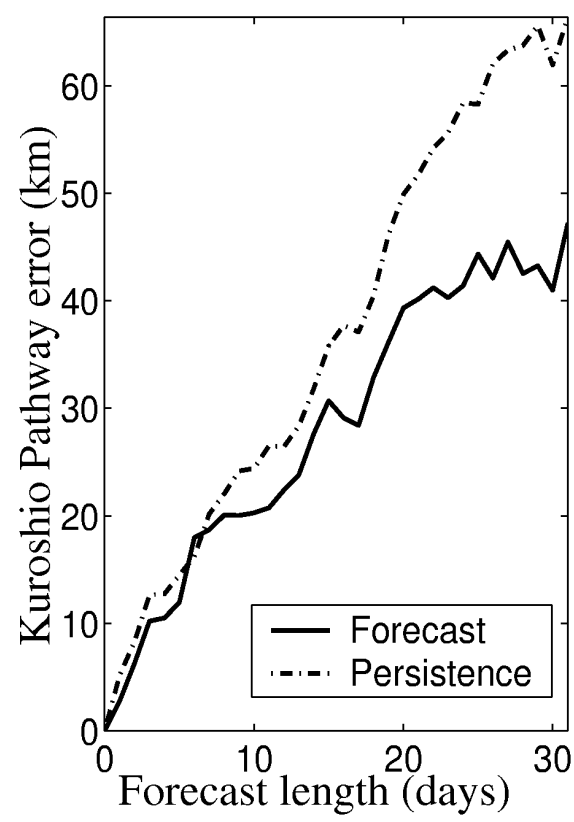

RMS SSH error vs Forecast length

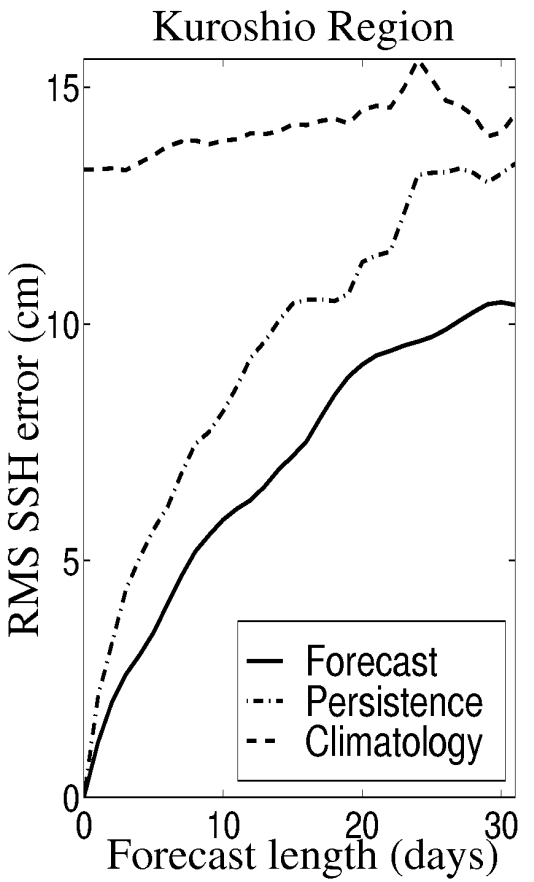

Pacific North of $20^{\circ} \mathrm{S}$

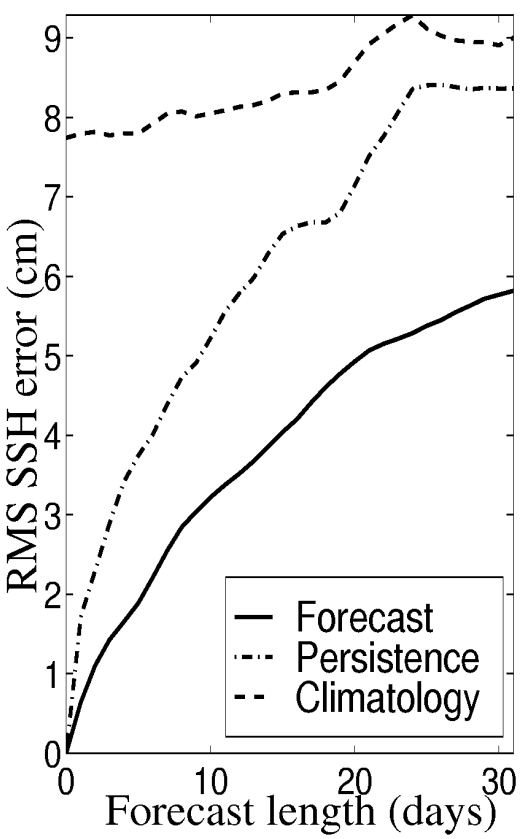

Fig. 4 : 1/16 ${ }^{\circ}$ Pacific SSH forecast verification against model with TOPEX and ERS-2 data assimilation. Forecast initialized from January 1, 1999.

Other key data types for near real time global eddy-resolving ocean prediction include SST and frontal locations from satellite IR imagery, hydrography and surface wind stress from scatterometry. Automated techniques exist for analyzing oceanic fronts seen in satellite IR (Cayula and Cornillion, 1995) and a rubber sheeting technique (Carnes et al., 1996) can be used to assimilate them into an ocean model. Assimilation of frontal location data can have a stronger impact than SST assimilation on model representation of circulation features with a frontal signature. While there will be insufficient synoptic hydrographic data to have major impact on the global depiction of mesoscale variabililty, the historical hydrographic database can be used to relate the more abundant SSH and SST synoptic data to subsurface thermohaline structure with substantial skill (e.g. Carnes et al.,1996). The profiling floats and the ARGO program should rapidly add to the historical database of relatively deep, high quality temperature and salinity profiles and provide increased accuracy in synthetic temperature and salinity profiles derived from SSH and SST.

This experience suggests operational oceanography for the navies is useful and doable. The routine, systematic and long-term delivery of products for the end-users ("ocean forecast bulletins") has also allowed end-users to be more precise specifying their requirements and to adapt their existing systems to operational oceanography products. They are thus ready to "ingest" the new products that will come from GODAE. The very high resolution needed and the effort needed to better integrate data and models is still, however, a very challenging objective which reinforces the need for the GODAE global and shared effort towards a true operational oceanography.

\section{3 - Marine Safety and marine meteorology}

Marine safety and marine meteorology are under the responsibility of national meteorological services. Depending on the organization prevailing in each country, marine safety activities can include environmental duties, protection or crisis management, such as container or oil spill drift forecast, fishery support and living resources management, or potential negative effects of waves and storm surges to the coastline. The main activity in marine meteorology main is to issue marine 
weather forecast bulletins or warning. This activity has evolved in the past years and is now closer to the mariner needs. It is starting to provide customer oriented services (e.g. by providing them with dedicated assistance, describing more accurately the marine atmosphere as well as the oceanic mixed layer accordingly to their activity needs). This implies services adapted to user needs, which always require a better knowledge of the atmosphere and the ocean. Most of the models used in marine meteorology intimately rely on a good representation of the oceanic conditions. This is true for the atmospheric models, general circulation models as well as limited area models at higher resolution, or specific models such as cyclone models. For all these models, thermal structures at surface and in the entire oceanic mixed layer must be well represented because of the strong interaction between the atmospheric and oceanic boundary layers. Shay et al. (1999) thus show how a warm eddy (observed by altimetry) contributed to the intensification of Hurricane Opal. Currents and other related dynamic parameters such as roughness of the surface are also important to improve the every day forecast. Drift, storm surge or wave models rely also heavily on precise knowledge of the ocean.

Models of the global ocean are the appropriate tool for integrating observations, both in time and space, and providing a dynamically and physically self-consistent estimate of the surface conditions. Models allow a proper description of the intimate mechanisms taking place in the mixed layer. The output from high-resolution models also allows a better representation of surface ocean currents with a direct consequence for ocean pollution monitoring and prediction. It is also likely that accurate upper ocean current forecasts could significantly improve the quality of sea state forecasts (current-wave interaction are known to be significant in several circumstances).

\section{4 - Fisheries}

Variations in marine environmental conditions affect the distribution, abundance and vulnerability of fish populations. The fishing industry needs information on the ocean in order to understand, model and predict the effects of ocean conditions on fish populations and to efficiently harvest marine fish stocks. This information can help localize zones with a higher probability of finding fish (e.g. frontal and upwelling regions). Knowing this, fishermen can reduce their search time and navigate directly towards the most favorable zones, thereby reducing their operation costs. Finding locations favorable to target species can also help to reduce bycatch (the amount of non-target species that are caught and thrown back into the sea). Thus, to minimize the cost of their fishing campaigns, fishermen need a description and short-term prediction (a few days) of the upper ocean at high space and time resolution (typically a few $\mathrm{km}$ to a few tens of kilometers and a few days). Maintaining sustainable fisheries is also a growing concern. International and national regulatory agencies and fisheries managers need information on the changing marine environment and its effect on fish populations (prediction of future states of target stocks) to effectively and rationally manage fisheries.

While neither the behavior of the ocean nor the behavior of fish is completely understood, there are several factors that are commonly recognized as having an impact on fishing success. A nonexhaustive list of important variable ocean parameters and features would include temperature, salinity, currents, ocean color, turbidity, mixed layer depth, fronts and eddies. Depending on the area and the species, the relative importance of the individual factors will change. It is for this reason that fishermen are often willing to cooperate in the collection of the needed information. While traditionally they tended to rely on information directly obtained from their fishing vessels, they have started to realize the benefits of using external information as it became operationally available. This occurred, in particular, with the advent of satellite oceanography. High resolution satellite Sea Surface Temperature (SST) maps (e.g. AVHRR) were thus one of the first external ocean products they used. SST maps provide useful information on mesoscale ocean flow field (fronts, eddies), position of the main current systems and regions of upwellings. More recently, satellite ocean color maps (e.g. SEAWIFS) became routinely available. Ocean color provides in an indirect way a measurement of phytoplankton concentration. As phytoplancton is the primary food 
and energy source for the ocean ecosystem, fishermen find good fishing spots in areas rich in phytoplankton. But like the SST maps, these maps are affected by the presence of clouds. The development of satellite altimetry and the recently demonstrated feasibility of real-time processing of these radar measurements have led to new ocean observation maps for the fishing industry. The spatial coverage of these maps is always complete as radar measurements are unaffected by the presence of clouds. They can provide a precise description of the mesoscale flow field (fronts, eddies) and a quantitative estimation of the surface geostrophic currents.

A global and integrated description of the ocean physics should allow the development of improved ocean products for fisheries, both for improved efficiency and for better management of stocks that are continually under pressure. Only in a very few localized areas are model and data assimilation products now available. One aim of GODAE is to extend the quality, comprehensiveness and availability of such products. New parameters not directly observed should be available (e.g. depth of the thermocline, deeper ocean currents, vertical velocities). Better estimation of directly measured parameters (e.g. sea surface temperature, ocean currents) is also expected because the model dynamics and different sources of data will be combined. The availability of global products means the global fishing industry will be able to work from a consistent base. It will allow fishermen to compare the value of different ocean parameters depending on the area and time.

\section{5 - Offshore industry}

The offshore oil and gas industry has a long tradition of gathering and using meteorological and oceanographic data. They are mainly used to establish design and operational criteria for field developments. Accurate data are of foremost importance because operations have to be performed in a safe and cost-effective manner. Ocean data and products required for the offshore exploration and production are both statistical and near real time products. In the exploration and development phases, statistical information is required to derive extremes for design criteria. Statistical analysis is also needed to derive operational criteria (duration or occurrence statistics, weather windows). Real time data are used in a day-to-day mode to plan and execute operations. These data are often combined with the previous observations, occurrence statistics and forecasts to take decisions on when operations will start or be cancelled.

Ocean parameters that will be considered for any data acquisition or simulation program in support of offshore industry are wave height, period and direction, current speed and direction with depth, tides, storm surge (sea level), sea temperature and salinity and ice cover (if relevant). Adequate data are obtained by specific in situ measurements from buoys and platforms (fixed and floating), remote sensing data, model simulations or historical data. Today, information mainly comes from in situ measurements but remote sensing data and numerical models are now playing a more important role in providing data for the industry. In the Gulf of Mexico, from which nearly half of all US domestic oil is extracted, currents (2-4 knots) associated with the Loop Current and its large eddies impact oil and gas exploration and production activities. There, offshore hydrocarbon industries have started to use both the near real-time altimeter products and an operational nowcast/forecast system relying on altimeter data assimilation (Kantha et. al., 1999; Digby et al., 1999).

GODAE aims to promote the development of a suite of new products which integrate in situ, remote sensing data and models. Of particular importance is the provision of better estimates of the vertical shear in ocean currents; this should allow a more limited and more focused deployment of in situ instrumentation (e.g. model validation, local effects not resolved by the models). GODAE will also be able to provide boundary conditions for localized high resolution models (see below).

The upper ocean current nowcasts and forecasts which will be provided by GODAE at a reasonably "high" resolution will also give potentially useful information for ship route planning, either in economic terms or for recreational yachting. The three dimensional structure of the ocean currents 
will also be of major interest for pipe-laying and cable-laying. Currents can put, for example, enormous pressure on the side of a ship, causing it to move during cable burial or payout.

\section{6 - Shelf and coastal applications}

All of the major marine activities, such as offshore oil and gas production, fishing, aquaculture, shipping and recreation are often concentrated near the coast or on the continental shelf. Preservation, pollution control and safe and efficient exploitation of these regions are therefore particularly important (IOC, 1998). This poses a specific problem in terms of ocean products as the ocean dynamics and the space and time scale of ocean phenomena in those regions are very different from those in the open ocean. The scales of motion and processes driving them depends, in part, on the distance from shore. Close to the coast and in estuarine waters, river outflows and upwelling due to along- or cross- shore winds are of great significance. Turbulent mixing by waves can penetrate to the sea floor and the advection and stratification of suspended particles needs to be modeled. Further from the coast, over the continental shelf, the baroclinic Rossby radius and hence cross-frontal scales are often only $2-5 \mathrm{~km}$. Over the shelf break are boundary currents, which are part of the open ocean circulation, and internal waves generated by tides impinging on the shelfbreak slope. Kelvin waves propagate along both the shelf-break slope and the coast. In all these regions tidal "forcing" at the boundary, waves propagating in from the open ocean and atmospheric fluxes of momentum and heat are important.

Dynamically based model systems for prediction of surface waves, tides and storm surges have been operational for more than a decade (Flather,1981). A number of three dimensional gridpoint (Greatbatch and Mellor,1999) and finite element (Carey,1995) models of the baroclinic structure have been developed and widely tested. A trial of some of these models for the Halten Bank region was conducted in 1988 (Hackett et al., 1995, Oey and Chen, 1992). Much of the development of the 3D models has been aimed at the oil and fishery industries. Oil production in the Gulf of Mexico and off the Norwegian and Scottish coasts has moved onto the shelf break. Production is severely affected by strong deep currents from internal waves, boundary currents and mesoscale eddies. Ecosystem models linked to coastal models could support fisheries in many regions (e.g. Grand Banks of Newfoundland, Greatbatch and Mellor, 1999; Halten Bank, Johannessen et al., 1989). Naval operations are also increasingly carried out near-to-shore. Finally local area forecasts close to shore are being developed using coupled ocean atmosphere models (Hodur, 1997) in the USA.

Shelf sea models are usually relaxed towards climatologies at their open ocean boundaries. Authors routinely indicate that their results must be degraded by lack of better boundary information. Davies and Lawrence (1994) investigate how the flow in their model of the Irish Sea depends on the inflow. Specific examples of flow on the shelf driven by time varying flows from the open ocean have been presented for the Gulf of Mexico (Oey, 1995) and the Halten Bank (Oey and Chen, 1992). In the Gulf of Mexico the loop current eddy shedding depends on the strength of the flow through the Yucatan peninsular (and hence on flow in the Atlantic) and drives time variations in the flow on the shelf. Variations in the positioning of the North Atlantic Current appear to influence the flow over the Halten Bank as suggested also by the studies of Haugan et al. (1991). High resolution models of the shelf break would, of course, be very dependent on the quality of fields at their open ocean boundaries.

The oceanographic data and the ocean data assimilation systems or methodologies supported by GODAE need to be used to constrain the deep ocean in these models and hence to contribute to the driving of the flow in the shelf-break, shelf and coastal waters. Coastal models should assimilate the deep oceanographic data and/or use data from the deep ocean GODAE systems at their open boundaries. The deep oceanographic fields which these models need are the ocean surface height (including tidal motions), and ocean temperatures, salinities and horizontal currents as a function of depth. GODAE will provide most of these fields globally. Any shelf/coastal application in the world should thus be able to use and test them. The exchange of information and experience 
between similar applications in different geographical areas will be essential to develop further the use of GODAE products for coastal/shelf applications.

\section{4 - GODAE REQUIREMENTS FOR AN OCEAN OBSERVING SYSTEM}

The global ocean observing system needed for GODAE and its applications is a difficult issue. First, there is not a unique answer and data needed to constrain an ocean model will generally depend on the application (e.g. mesoscale versus large-scale climate). There is, however, a convergence of opinion concerning requirements (science and applications) that raises hope that a common specification for a permanent, global and real time ocean observing system could be agreed. This Conference is indeed working toward that goal.

The GODAE initial requirements and a strategy for a global observing system (remote sensing and in-situ) are summarized below. It is important to realize that as GODAE develops, more specific requirements should be made on the basis of improved understanding of data utility. Today requirements are mainly based on the analysis of non-integrated systems. That is, the estimates of sampling requirements take no account of models and assimilation that can alter the spatial and temporal requirements (e.g. using a model forecast as an a priori knowledge instead of climatology).

Global ocean state estimation systems are an appropriate, and powerful means to assess the impact of the observing system for its applications (scalability of the observing system), to identify gaps (redirect/improve sampling in geographical areas, define new parameters to be measured) and to improve the efficiency/effectiveness of the observing system (adoption of new observing techniques, e.g. space based salinity measurements, Lagrangian versus Eulerian observations). Through the development of applications and users, it will become essential to sustain a global observing system.

\section{1 - Remote Sensing Data}

Remote sensing data provide the only real avenue to global coverage on the space and time scales of interest for GODAE. They can provide near real-time, long-term, repeated (synoptic) and global measurements of key parameters (e.g. sea level and ocean circulation, SST, winds) (Fig. 5). Some techniques are very mature (SST, altimetry) and can be readily used to constrain OGCMs. The availability of "good" satellite remote sensing data and the know-how of the corresponding scientific community are thus among the main drivers of GODAE. For the GODAE time frame, space systems are already mostly decided. GODAE has requirements on products (accuracy, delivery) and should provide guidance for future systems. An initial design of the remote sensing observing system has been proposed as GODAE initial requirements to CEOS (GODAE is one of the Pilot Projects of the CEOS Integrated Global Observing Strategy). It is generally based on an analysis of sampling characteristics and of impact in models so that satellite data can represent the main space and time scales of observed signals with the required accuracy. In that sense, these requirements fit with the two main applications foreseen for GODAE (climate and mesoscale).

GODAE will also depend on several products available via numerical weather prediction, including wind stress estimates (high priority though scatterometry may offer a more direct route) and surface heat and moisture flux estimates (important but not essential). The requirements for operational meteorological satellites will be set by meteorological agencies but they should be aware of the indirect needs of GODAE. 


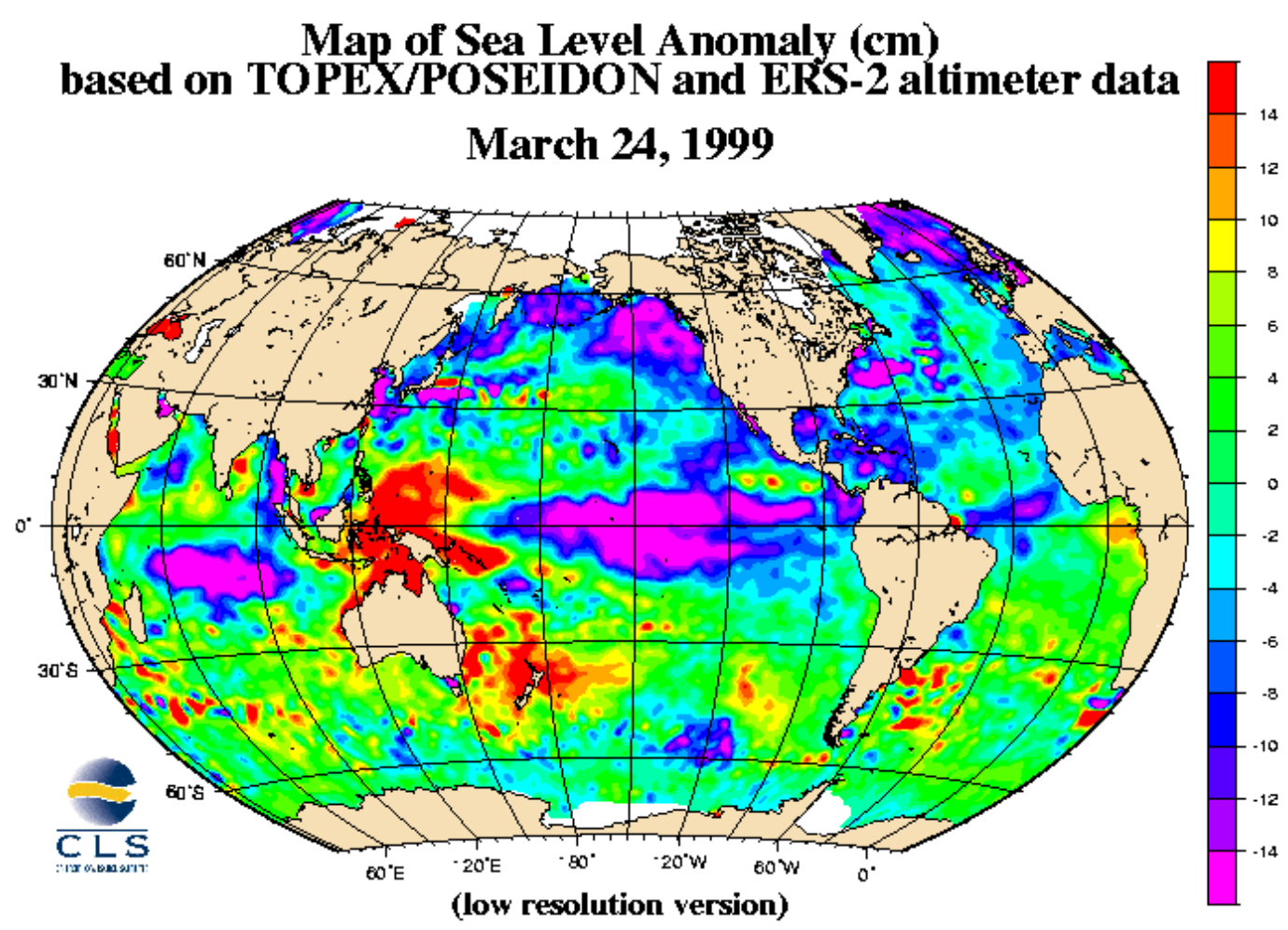

Fig. 5 : Sea Level Anomaly map obtained from the CLS DUACS near real time altimeter data processing system.

GODAE remote sensing data requirements can be summarized as follows:

\section{a. Sea Surface Topography (Altimetry)}

GODAE requires global, near real time, high accuracy and high resolution observation of sea surface topography. It requires at least two (and preferably three) altimeter missions with one very accurate long term altimeter system to provide a reference for the other missions. The combination of several altimeters is needed to constrain the ocean mesoscale circulation (Fig.6). T/P and ERS-2 combined can provide a mapping of the ocean circulation with a formal error below $15 \%$ of the signal variance (Le Traon and Dibarboure, 1999). They have thus the ability to control a global eddy resolving model. In the time frame of GODAE, Jason-1 (then Jason-2) and ENVISAT the successors of T/P and ERS-1/2 will provide data sets with the same sampling as their predecessors but with an enhanced real time data processing and an improved accuracy.

\section{b. Geoid estimation}

GODAE needs improvement of geoid estimation to get absolute dynamic topography. Satellite gravity missions would be a valuable contribution to oceanography and, in particular, to the exploitation of the altimetric component of the observing system. A one-off set of experiments (CHAMP, GRACE and GOCE) would meet GODAE requirements but also the long-term requirements of the operational observing system : combination of data from these three missions (CHAMP and GRACE mainly for scales $>500 \mathrm{~km}$, and GOCE mainly for scales between 100 and $500 \mathrm{~km}$ ) with in situ and altimeter data should allow the estimation of mean dynamic topography with an accuracy of about $1 \mathrm{~cm}$ rms. 


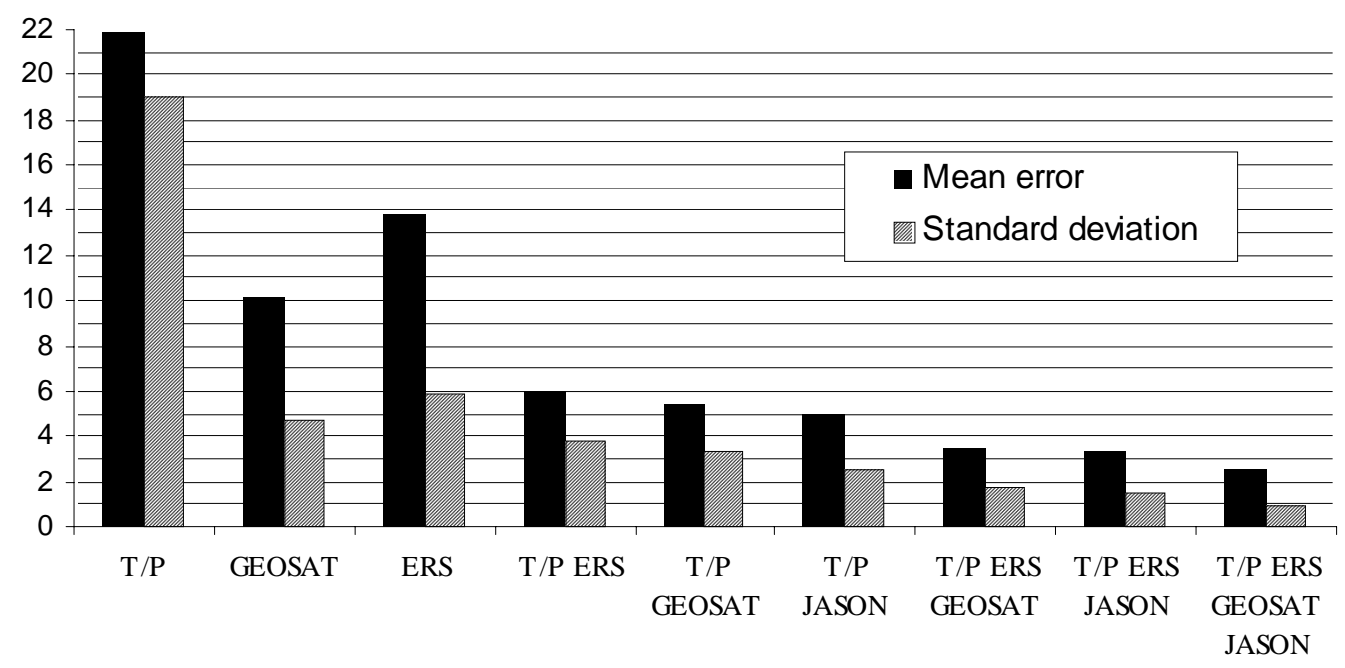

Fig. 6 : Mean and standard deviation of Sea Level Anomaly mapping error for single and multiple altimeter missions. Units are percentages of signal variance (from Le Traon and Dibarboure, 1999).

\section{c. Wind Vectors}

GODAE requires wind vectors measurements. The number of instruments required is in part dependent upon the ability of numerical weather prediction to enhance and add value to the information provided by a single instrument. While it may be hard to justify a second instrument on the basis of GODAE or climate alone, considered in conjunction with the needs of mesoscale meteorology and regional oceanography, the case seems very strong. One strong concern is the continuity of wind vectors measurements.

\section{d. Sea Surface Salinity}

GODAE requires global Ocean Salinity observation. Observation of this key variable for oceanography is seriously lacking; phase 0/A studies of satellite missions proposals for ocean salinity observation (e.g. HYDROSTAR/ESTAR, SMOS) show that low frequency microwave radiometry is a viable concept compatible with satellite observation. An integrated approach for ocean salinity, based on the combination of in situ and satellite observations, would meet the experiment objective.

\section{e. Sea Surface Temperature}

GODAE requires Global High Resolution Sea Surface Temperature in near real time for validation purposes and assimilation into ocean models. Missions planned in the near future appear to meet GODAE needs in term of observation and accuracy; priority is given to the constitution and diffusion to users in real time of synthetic products. GODAE needs the availability of a Global Analysed SST field (merging different satellite products, and in situ data) to High Resolution in time (diurnal cycle resolved) and space (at least $10 \mathrm{~km}$ ).

\section{f. Surface Radiation}

GODAE needs access to surface radiation data to complete the determination of the thermal boundary conditions. A daily global, real-time product of Surface Short and Long Wave Radiation is required to describe scales of around $200-300 \mathrm{~km}$. The latter are essential to help improve surface flux products from Numerical Weather Prediction Centers and estimate their error statistics for input to the assimilation process.

\section{g. Sea Ice products}


These should be useful for some GODAE applications. Existing products (sea ice extent, sea ice concentration) are satisfactory at least for the present time.

\section{2 - In Situ}

The existing in-situ global ocean observing system is clearly insufficient and inadequate for the global scope of GODAE. The development of an appropriate network must take into account the complementarity between the in-situ and remote sensing data : vertical structure from in-situ data, surface information from satellites, different samplings, different measurement contents, calibration and validation of space measurements with in-situ data. This is also true for remote sensing. The initial design should also assess the information content of all the existing and planned networks and to ascertain the potential of these to satisfy the requirements of GODAE. Finally, it should coordinate with GOOS and GCOS and with relevant research programs of the WCRP and, in particular, seek synergism and complementarity with observing plans of CLIVAR. This is a clear function of this Conference.

The ARGO proposal (a joint GODAE and CLIVAR initiative) was developed specifically with these weaknesses in mind. ARGO will be the main direct global data stream for GODAE (Roemmich et al, this issue). It will complement the existing operational and experimental systems in the equatorial regions set up for ENSO prediction (TAO, TRITON, PIRATA) (McPhaden et al., this issue) and the ship-of-opportunity XBT program (Smith et al, this issue). An improved sampling in western boundary currents will be required (Imawaki et al., this issue) and the array will also be usefully complemented by other measurements (e.g. drifters, time series stations) (Niiler et al., this issue; Send et al., this issue). The development of an in situ surface flux verification data set is also important for GODAE, in particular to document the errors in momentum and, especially, heat and moisture flux products from Numerical Weather Prediction (NWP) centers.

This observing in-situ system has been designed mostly with large-scale, low-frequency phenomena in mind. A global in-situ observing system resolving the mesoscale is, however, clearly not feasible and obviously not cost-effective (at least with existing technology). How useful will the in-situ observing system be for the global ocean description at the mesoscale that is needed for GODAE applications ? This is an open issue but there are good grounds for being optimistic. The remote sensing system (mainly altimetry and SST) has the potential to resolve the mesoscale field at the surface (see also discussion in section 3.2). The in-situ system will provide a constraint for the large scale thermohaline field that can condition the development of mesoscale variability (e.g. through baroclinic instability). An "intelligent" combination of in-situ and remote sensing data through effective data assimilation should thus help to resolve the 4D mesoscale field. The in-situ observing system (in particular ARGO and the high-density XBT lines) while not resolving the mesoscale will also be able to resolve the statistics of the mesoscale variability (space/time scales, vertical structure and contribution of barotropic/baroclinic components). This statistical information will be of great importance for an effective assimilation of altimeter data. The large-scale in-situ observing system is thus expected to be useful for mesoscale applications but the impact need to be better quantified. As importantly, this long-term observing system will be the background system on which regional applications will implement, if needed, complementary and dedicated high resolution observing systems.

\section{5 - SCIENTIFIC AND TECHNICAL ISSUES}

\section{1 - Scientific issues}

As outlined in section 3, there are a number of important scientific issues which are raised by the development of operational oceanography and its applications. There are first scientific issues 
related to the data themselves. There is a need to improve data quality, work on data errors, develop/test improved processing techniques and to better understand the data information content (e.g. profiling float and altimetry). There is also a need to prepare improved forcing fields combining satellite and NWP products and improved climatologies to initialize and/or constrain models. Scientific issues dealing with the development of advanced models and efficient/effective assimilation schemes are discussed in Stammer, Fukomori and Wunsch (1998) and Stammer et al. (this issue). These challenging issues are crucial to the success of GODAE. A data assimilation working group will be established to develop and test assimilation schemes from the global set of regional experiments. The work will include Observing System Simulation Experiments (OSSEs) to assess the impact of the observing system (space/in situ) on the different GODAE applications (large-scale, mesoscale). Scientific issues on the predictability of the ocean both at mesoscale and at large scale are also important to determine the validity/impact of GODAE products. We also need to better assess how the predictability of coastal/regional models will be improved by using boundary conditions derived from global models. This subject is addressed, particular, in the GANES (1999) EC project. A European Shelf Seas Ocean Data Assimilation Experiment (ESODAE, 1999) is also being developed to coincide with and take advantage of boundary data provided by GODAE.

\section{2 - Technical issues}

GODAE also must face several key technical issues (access to large computer facilities, communication systems, data flow organization,...). These technical challenges should not be underestimated. They will push the capability of the state-of-the-art assimilation and require a substantial increase in the computational resources available to the ocean community. Some estimates of the required resources are given in Stammer et al. (this issue). Here we will focus on issues relevant to the data flow (input data, model/assimilation products, products for end-users) which require international coordination and a major and direct effort of GODAE. The GODAE data flow as it is envisioned now is summarized in the sketch below (Fig. 7). There will be several GODAE centers, for example, in the US, Japan, Europe and Australia (GODAE partners). A GODAE center will be involved in research and development in global data assimilation and in exchange, comparison and cross-validation of results with the other GODAE centers. It will be associated/linked with one or several application or service provider centers. Several data centers (e.g. profiling floats, altimetry, NWP products, SST,...) will collect, quality-control and organize real time (e.g. internet, GTS) and delayed time data flow. Data including model outputs will be disseminated through one or several GODAE data servers.

A GODAE data team will be formed to work on the data flow issues. One of the first tasks will be to define the way to populate the GODAE data server(s) : which data streams, timeliness, retention period, level of quality-control, data versions, real time and delayed mode data should be included ? What level of coordination and redundancy is needed between different GODAE data servers ? The data team will also have to analyze the long-term data archive needs and the interaction between data centers and GODAE centers (feedback on data quality, data error statistics). The relationship between GODAE centers, application centers and end-users will have to be precisely defined. This is crucial for the success and visibility of GODAE. GODAE regional pilot experiments as the one foreseen as part of the Eurogoos Atlantic Task team (Le Provost, 1999) will be a good means both to gain experience on real-time data flow aspects and to begin product design and product distribution in response to user specifications. 


\section{GODAE DATA FLOW}

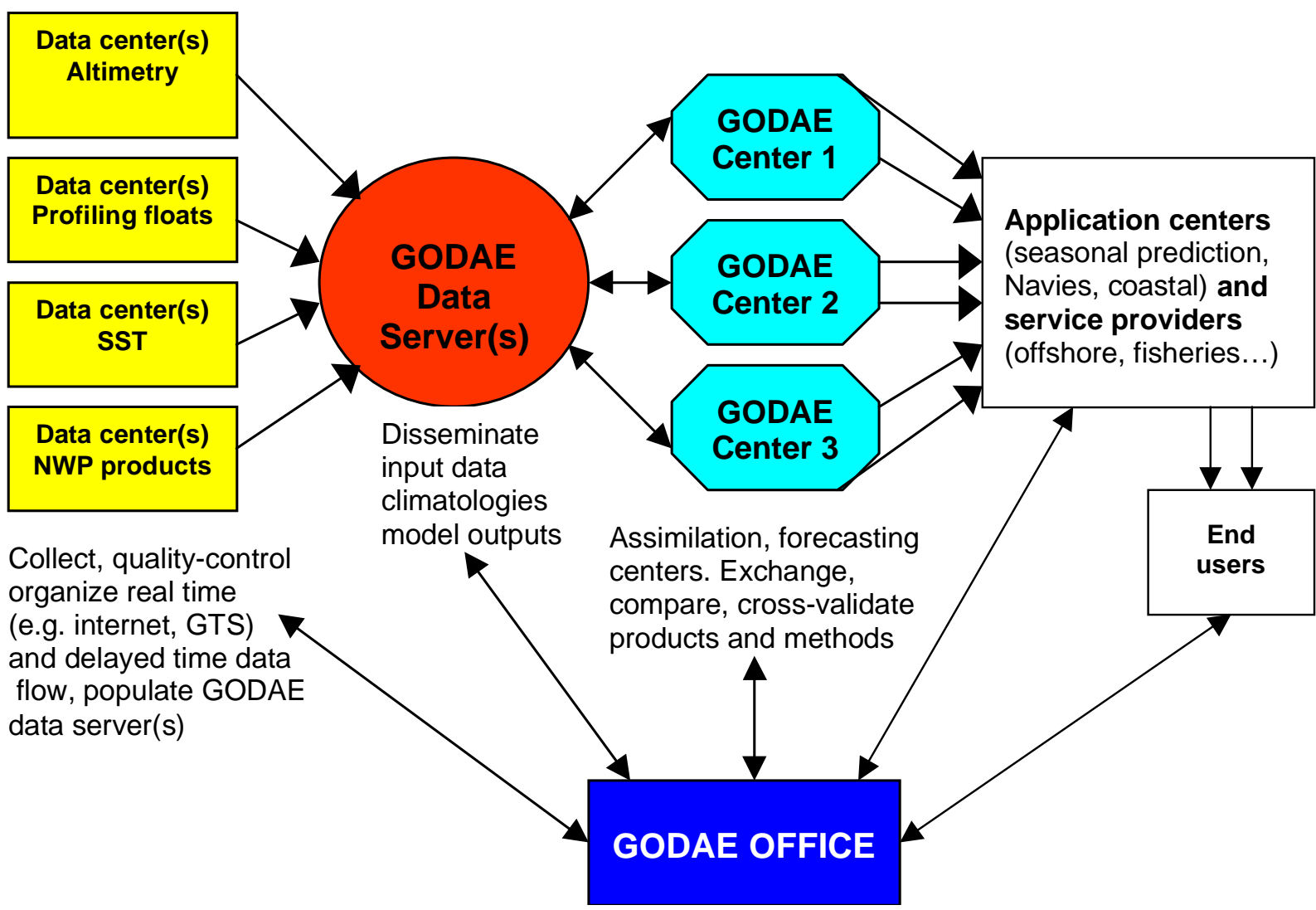

Fig. 7 : GODAE Data Flow

\section{6 - CONCLUSION}

We believe a global and integrated approach will be highly beneficial to the development of operational oceanography applications. Such systems will provide a new suite of products for seasonal climate analyses and predictions, mesoscale open ocean applications and coastal/shelf applications. The global domain opens up a broader user base and minimizes the investment needed to develop a service for a particular sector of the user community. For most of the expected applications, there is a convergence and commonality among the users requirements, i.e. a global ocean product will serve a large user community. New applications (and users) are also likely to develop when products become operationally available. As importantly, there is a strong convergence between operational (user driven) and research (science driven) applications : integrated analyses are needed for developing improved understanding of the oceans.

The development of a global, near-real time ocean observing system in phase with GODAE planning is essential to the success of GODAE. The observing system being contemplated now (and at this Conference) appears to meet the main GODAE requirements. When GODAE develops, a better analysis of data utility and data needs will be possible and more specific requirements will be made. Through the development of applications and users, GODAE will become a powerful means for the scalability, the maintainability and sustainability of the observing system. Although GODAE still faces many challenging scientific and technical issues, elements of implementation are starting at national levels and the project is moving rapidly in the right direction. Coordination of national activities, organization of the data flow, and the start of pilot projects (e.g. on data assimilation) and pilot experiments will be essential tasks for the coming year. 


\section{7 - REFERENCES}

[Behr 98] D. W. Behringer, M. Ji, and A. Leetmaa : "An Improved coupled model for ENSO prediction and implications for ocean initialization. Part I: The ocean data assimilation system”. Mon. Wea. Rev., 126, 1013-1021, 1998.

[Care 95] G. F. Carey : "Finite Element Modelling of Environmental Problems". Wiley, New York, $1995,378 \mathrm{pp}$.

[Carn 96] M.R. Carnes, D.N. Fox, R.C. Rhodes, and O.M. Smedstad : "Data assimilation in a North Pacific Ocean monitoring and prediction system", Modern Approaches to Data Assimilation in Ocean Modeling, ed. by P. Malanotte-Rizzoli, Elsevier, 61, 319-345, 1996.

[Cayu 95] J.F. Cayula, and P. Cornillon : "Multi-image edge detection for SST images". J. Atmos. Ocean. Tech., 12, 821-829, 1995.

[Chen 95] D. Chen, S.E. Zebiak, A.J. Busalacchi, and M.A. Cane : “An improved procedure for El Nino forecasting". Science 269, 1699-1702. 1995.

[Clan 97] R.M. Clancy, and P.F. Moersdorf : "An overview of operational modeling at Fleet Numerical Meteorology and Oceanography Center".Monitoring the oceans in the 2000s : an integrated approach, International Symposium, Biarritz, October 15-17. 1997.

[Coop 88] N.S. Cooper: "The effect of salinity on tropical ocean models". J. Phys. Oceanogr., 18, 697-707. 1988.

[Davi 94] A. M. Davies and J. Lawrence : "The response of the Irish Sea to boundary and wind forcing : results from a three-dimensional hydrodynamic model". J. Geophys. Res., 99, C11, 22665-22688. 1994.

[Digb 99] S. Digby, T. Antczak, R. Leben, G. Born, S. Barth, R. Cheney, D. Foley, G.J. Goni, G. Jacobs, and N. Shay: "Altimeter data for operational use in the marine environment". IEEE/MTS Conference Oceans 99, Seattle, September 1999.

[Enfi 96] D.B. Enfield : "Relationships between inter-American rainfall to tropical Atlantic and Pacific SST variability". Geophys. Res. Lett., 23, 3305-3308. 1996.

[ESOD 99] ESODAE,http://www.met-office.gov.uk/sec5/ESODAE/ESOHOME.html. 1999.

[Flat 81] R. A. Flather : " Practical surge prediction using numerical models". In Floods due to high winds and tides, editor D. H. Peregrine, 21-43. Academic Press, London. 1981.

[GANE 99]GANES, http://mist.met.ed.ac.uk/ganes.html. 1999.

[Gira 97] S. Giraud, S. Baudel, E. Dombrowsky, and P. Bahurel : "The SOPRANE project : Real-time monitoring of the North-East Atlantic - ocean circulation nowcast-forecast for oceanographic scientific campaigns".Monitoring the oceans in the 2000s : an integrated approach, International Symposium, Biarritz, October 15-17. 1997.

[Grea 99] Greatbatch R. J. and G. L. Mellor : "An overview of coastal ocean models". Coastal and Estuarine Studies, 56, 31-57. 1999.

[Hack 95] Hackett, B., L. P. Roed, B. Gjevik, E. A. Martinsen and L. I. Eide : "A review of the Metocean modeling project (MOMOP) Part 2: Validation study". Coastal and Estuarine Studies, 56, 307-327. 1995.

[Hast 93] Hastenrath, S., and L. Greishar : "Further work on the prediction of Northeast Brazil rainfall anomalies" J. Clim., 6, 743-758. 1993.

[Haug 91] Haugan P. M., G. Evensen, J. A. Johannessen, O. M. Johannessen, and L. H. Petterson : "Modeled and observed mesoscale circulation and wave-current refraction during the 1988 Norwegian Continental Shelf Experiment". 1991.

[Hodu 97] Hodur, R.M. : "The Naval Research Laboratory's Coupled Ocean/Atmosphere Mesoscale Prediction System (COAMPS)". Monthly Weather Review, 125, 1414-1430. 1997.

[Hurl 99] H.E. Hurlburt, O.M. Smedstad, R.C. Rhodes, J. F. Cayula, and C.N. Barron: “A feasibility demonstration of ocean model eddy-resolving nowcast/forecast skill using satellite altimeter data“. NRL Technical Memorandum, Nav. Res. Lab., Stennis Space Center, Miss., in press, 1999. 
[IOC 98] IOC : “The GOOS 1998”. IOC, Paris, 1998, 168 pp.

[Ji 98] Ji, M., D. W. Behringer, and A. Leetmaa : "An Improved Coupled Model for ENSO Prediction and Implications for Ocean Initialization. Part II: The coupled model". Mon. Wea. Rev., 126, 1022-1034. 1998.

[Ji 99] Ji, M., R. W. Reynolds and D. W. Behringer : "Use of TOPEX/POSEIDON sea level data of ocean analyses and ENSO prediction: some early results". J. Climate, (in press). 1999.

[Joha 89] Johannessen, J. A., O. M. Johannessen, and P. M. Haugan : "Remote sensing and model simulation studies of the Norwegian coastal current". Int. J. Remote Sens., 10(12), 1893-1906. 1989.

[Kant 99] Kantha, L.K., J.-K. Choi, R. R. Leben, C. Cooper, M. Vogel and J. Feeney, "Hindcasts and Real-time Nowcast/Forecasts of Currents in the Gulf of Mexico", Proceedings of the Offshore Technology Conference, Houston, TX, May 3-6, 1999.

[LeTr 99] Le Traon, P.Y., and G. Dibarboure : "Mesoscale mapping capabilities from multiple altimeter missions". J. Atm. Ocean. Tech., 16, 1208-1223. 1999.

[LePr 99] Le Provost, C. : "Forecasting the Atlantic: Towards an Atlantic pilot experiment". Second Conference on EuroGOOS, Rome, 1999.

[Maes 98] Maes, C. : "Estimating the influence of salinity on sea level anomaly in the ocean". Geophys. Res. Lett., 25, 3551-3554. 1998.

[Phad 98] McPhaden, M.J., and coauthors: "The Tropical Ocean-Global Atmosphere observing system: A decade of progress". J. Geophys. Res., 103,14169-14240. 1998.

[Meye 91] Meyers, G., H. Phillips, Smith, N.R., and J. Sprintall : "Space and time scales for optimum interpolation of temperature -Tropical Pacific Ocean. Progr." Oceanogr., 28, 189-218. 1991.

[Oey 95] Oey, L.-Y. : "Eddy- and wind- forced shelf circulation". J. Geophys. Res., 100, C5, 8621-8638. 1995.

[Oey 92] Oey, L.-Y., and P. Chen : "A nested-grid ocean model: with application to the simulation of meanders and eddies in the Norwegian coastal current". J. Geophys. Res., 97, C12, 20063-20086. 1992.

[Shay 99] Shay, L K, G. Goni, and P.G. Black. "Effects of a Warm Oceanic Feature on Hurricane Opal". Monthly Weather Review (in press), 1999.

[Smed 99] O.M. Smedstad, J.F. Cayula, H.E. Hurlburt, R.C. Rhodes, and C.N. Barron : "Assimilation of satellite altimeter data by a high resolution model of the Pacific Ocean". Proceedings of the 3rd WMO international symposium on assimilation of observations in meteorology and oceanography, Quebec City, Canada, 7-11 Jun 1999, in press, 1999.

[Smit 91] Smith, N.R., J.E. Blomley and G. Meyers : "A univariate statistical interpolation scheme for subsurface thermal analyses in the tropical oceans". Progr. Oceanogr., 28, 219-256. 1991.

[Smit 97] Smith, N, and M. Lefebvre : "The Global Ocean Data Assimilation Experiment" (GODAE). Monitoring the oceans in the 2000s : an integrated approach, International Symposium, Biarritz, October 15-17. 1997.

[Stam 98] Stammer D., I. Fukumori and C. Wunsch : "Large Scale Ocean State Estimation" WOCE report N+ 161/98, GODAE Report $N^{\circ} 2,1998$.

[Stoc 97] Stockdale, T.N. : "Coupled ocean-atmosphere forecasts in the presence of climate drift". Mon. Wea. Rev., 125, 809-818. 1997. 